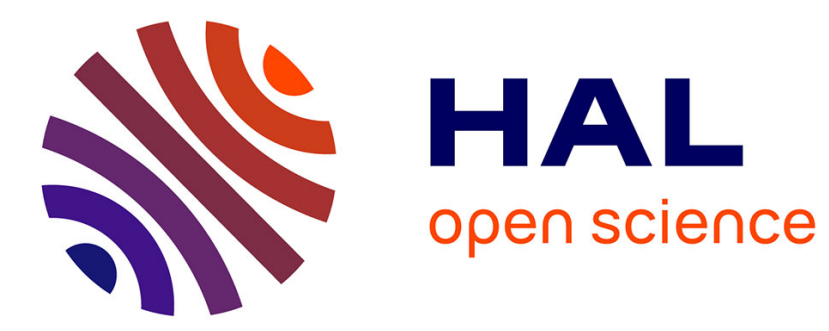

\title{
INTERNAL FRICTION ASSOCIATED WITH PRECIPITATION AND RECRYSTALLIZATION
}

\author{
R. Schaller, W. Benoit
}

\section{To cite this version:}

R. Schaller, W. Benoit. INTERNAL FRICTION ASSOCIATED WITH PRECIPITATION AND RECRYSTALLIZATION. Journal de Physique Colloques, 1983, 44 (C9), pp.C9-17-C9-27. 10.1051/jphyscol:1983902 . jpa-00223324

\section{HAL Id: jpa-00223324 https://hal.science/jpa-00223324}

Submitted on 1 Jan 1983

HAL is a multi-disciplinary open access archive for the deposit and dissemination of scientific research documents, whether they are published or not. The documents may come from teaching and research institutions in France or abroad, or from public or private research centers.
L'archive ouverte pluridisciplinaire HAL, est destinée au dépôt et à la diffusion de documents scientifiques de niveau recherche, publiés ou non, émanant des établissements d'enseignement et de recherche français ou étrangers, des laboratoires publics ou privés. 


\title{
R. Schaller and W. Benoit
}

Institut de Génie Atomique, Swiss Federal Institute of Technology, PHB-Ecublens, CH-1015 Lausanne, Switzerland

\begin{abstract}
Résumé - L'étude de la précipitation dans les alliages à base d'Al et de Cu par mesures de frottement intérieur montre que les stades de précipitation peuvent être détectés par l'apparition ou la disparation de pics de relaxation qui sont dus soit à la solution solide (pics de zener) soit aux précipités. Pendant longtemps, il a été ad̉mis que tous les pics dus aux précipitês avaient la même origine, c'est-à-dire étaient dus à des relaxations anélastiques aux interfaces précipités-matrice (théorie de schoeck). En fait le problème est plus complexe. Les caractéristiques des pics de précipités peuvent être différentes d'un alliage à l'autre. Des résultats ont été obtenus qui rendent compte de relaxations à l'intérieux des précipités ou encore de mécanismes d'interactions dislocations-précipités.

L'évolution du réseau de dislocations au cours de la recristallisation modifie profondément les valeurs du frottement intérieur. En particulier, on observe que la recristallisation apparaît après un accroissement du frottement intérieur. Ce résultat apporte un nouveau critère de recristallisation : la recristallisation est conditionnée par un accroissement de la mobilité des dislocations. De ce point de vue, le frottement intérieur devient une des meilleures méthodes pour étudier les interactions précipitation-recristallisation.
\end{abstract}

Abstract - The study of precipitation in Al and $\mathrm{Cu}$ based alloys by internal friction measurements shows that the precipitation stages can be revealed by the appearance or disappearance of relaxation peaks due either to the solid solutions (Zener peaks) or to the precipitates.

For a long time, it has been thought that all the peaks due to the precipitates have the same origin, i.e. are due to anelastic relaxations at the boundaries of the precipitates (Schoeck's theory). It is shown that the problem is more complex. The characteristics of these "precipitates peaks" can be different depending on the alloy. Some results, which give an account for relaxations inside the precipitates and also for mechanisms of interactions between dislocations and precipitates, have been obtained.

The evolution of the dislocations network during recrystallization modifies strongly the values of the internal friction background. In particular, the results show that recrystallization occurs after an increase of the internal friction. This leads to a new criterion for recrystallization : recrystallization is conditioned by the increase of the dislocations mobility. From this point of view, internal friction seems to be one of the better method for studying the interactions between precipitation and recrystallization.

INTRODUCTION - Precipitation and recrystallization are the two main solid-state transformations of aluminium and copper based alloys, which condition the quality of the semi-finished product.

Internal friction measurements, which are particularly sensitive to the evolution of microstructure of the materials [1], have been advantageous in the determination of the precipitation stages of various alloys, or in the study of the evolution of the 
dislocation network during recrystallization. Yet, it has to be noted that, during these last ten years, internal friction has not been used extensively in the study of precipitation and recrystallization. Indeed workers, who are concerned with diffusion assisted phase transformations, prefer more direct or easier methods as for example transmission electron microscopy, hardness, electrical resistivity or thermoelectric power.

In comparison with these more classical techniques, the disadvantage and simultaneousIy the advantage of internal friction is that the characteristic spectra of alloys can be affected by all kinds of evolutions of the microstructure. Therefore the interpretation of the anelastic phenomena is sometimes difficult. The interpretation of the internal friction spectrum and of its modifications during the transformation requires generally comparisons with the results obtained by the other techniques. In this context, the research of the anelastic mechanisms can bring precious informations on the micxoscopic mechanisms which are involved in the transformation itself.

Usually the internal friction spectrum of the aluminium alloys is composed of relaxation peaks, which are due either to the solid solutions (Zener peaks) or to the precipitates, and of a background which can sometimes be considered as the low temperature part of a high temperature peak due to dislocations [2].

The relaxation peaks inform on the diverse phases which appear in the alloy during ageing. The evolutions of the background and simultaneously of the elastic modulus can express the changes in the mechanical properties.

From this point of view, internal friction is very well suited to the study of the transformations in which are involved some problems related to the dislocations mobility : precipitation hardening, annealing out of the defects after deformation, recrystallization.

II. PRECIPITATION : Experimental results

a) Aluminium alloys :

Among the aluminium alloys, the most studied system has certainly been Al-Cu, especially with a concentration of $4 \mathrm{wt} \% \mathrm{Cu}[3$ to 7$]$. The precipitation of the $\theta$ phase follows the sequence:

$$
\alpha_{\text {AlsSS }} \rightarrow \text { GP } \rightarrow \theta^{\prime} \rightarrow \theta \cdot \rightarrow \theta
$$

The GP zones are thin clusters rich in $\mathrm{Cu}$, parallel to the (100) planes of the matrix and coherent. The $\theta$ ' precipitates are platelets of tetragonal structure and coherent. The $\theta^{\prime}$ differs from the $\theta^{\prime \prime}$ precipitates by the loss of coherency on the lateral faces, where interface dislocations appear in order to release the misfit. Finally, $\theta$ is the stable configuration of the $\mathrm{Al}_{2} \mathrm{Cu}$ tetragonal equilibrium phase. $\theta$ is incoherent.

Hanauer et al [5] have studied this precipitation sequence through the evolution of the internal friction spectrum (fig. 1). A first relaxation peak $\mathrm{P}_{I}$ is associated with the solid solution. Aftex the reversion of the GP zones, this peak is stable. It appears at $185^{\circ} \mathrm{C}$ for a frequency of $\mathrm{llHz}$. It is a Zener peak [8], because its height is proportional to the square of the $\mathrm{Cu}$ concentration in solution.

$P_{1}$ peak is still present in the alloy after the appearance of the GP zones. Its height is even too great, if the anelastic relaxation is only due to the cu atoms which remain in the solid solution. In this case, Hanauer et al think that this zener peak must also be due to some stress induced ordering in the GP zones. $P_{1}$ peak disappears and the internal friction background goes down, when the $\theta$ '' precipitates appear. The $\theta$ ' precipitates give rise to a strong increase of the background above $200^{\circ} \mathrm{C}$ and to the appearance of a second relaxation peak $\mathrm{P}_{2}$. The height of this peak is proportional to the volume fraction of $\mathrm{Cu}$ which has precipitated. The relaxation is then attributed to the movement of the interface dislocations at the boundaries of the $\theta$ ' precipitates.

$P_{2}$ peak vanishes during the precipitation of $\theta$. Internal. friction increases then monotonously with the temperature. 


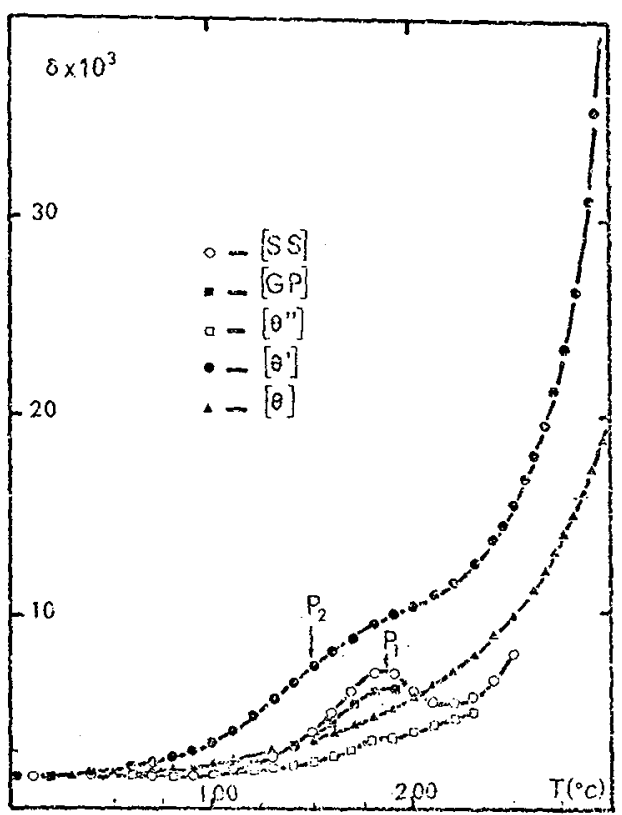

Eig. I : Characteristic evolution of the internal fxiction during precipitation in AI-4wtocu (after C. Hanauer, et al [5]).
In case of $\mathrm{Al}-4 \mathrm{wt}: \mathrm{Cu}$, the precipitation stages are very well marked by the evolutions of the internal friction spectrum. In other systems, the obtained results are not so clear.

For example, the Al-Mg binary alloys exhibit a relaxation peak after ageing [9,10, 11] Belson et al [11] show that this peak is not due to the precipitation of the $B$ phase $\left(\mathrm{Al}_{3} \mathrm{Mg}_{2}\right)$. Effectively, the peak is also observed after quenching but at lower temperature. The shift in temperature of the peak is attributed to the presence of vacancies which are in excess in the quenched specimen. On the other hand, the peak height depends Iinearly on the product of the square of the concentrations $\mathrm{C}_{\mathrm{Al}}^{2} \cdot \mathrm{C}_{\mathrm{Mg}}^{2}$. From these considerations, Belson et al attribute the origin of the peak to a zener type relaxation which can be described by the more general model of Leclaire and Lomer [12]. Zener type relaxations affected by the presence of the quenched-in vacancies have also been detected in other aluminium alloys which contain silicon atoms.

In A1-si single crystals, Entwistle et al [13] have observed a broad peak after treatments which are susceptible to form fine precipitates of $\mathrm{si}$ around the vacancies. The peak is then interpreted as due to the relaxation of the "si-vacancy" elastic dipoles.

In Al-Cu-Si-Mg, a peak is growing during ageing near room temperature. Elliott and Entwistle [14] attribute the origin of this peak to a stress induced ordering mechanism in the zones which are formed by solute atoms and vacancies. The peak is a zener peak because its height varies linearly with the square of the Mg concentration. A peak is also observed after ageing in an Al-Mg-Si industrial alloy [15]. This peak seems to be due to relaxations in the $B\left(M_{2} S_{i}\right)$ precipitates. These relaxations are favoured by the presence of vacancies in the precipitates.

Precipitation can also modify the internal friction without giving rise to relaxation peaks. In Al-Zn alloys, the internal, friction background increases during precipitation. Nowick [16] has attributed this increase to the precipitation of the $B$ phase at the grain boundaries. By means of microcreep experiments, he has shown that the anelastic strain does not reach an equilibrium value. He explained then this behaviour by the idea of coupled relaxations. Through the evolutions of the internal friction background, Merlin and al [17] determined four precipitation stages associated with the diverse precipitates (GP, $R, \alpha^{\prime}$ and $B$ ) in $A 1-25$ and 30 wto $2 \mathrm{n}$.

\section{b) Copper alloys :}

The study of precipitation by internal friction has also been performed in some copper based alloys. Peaks have been obsexved owing either to the solid solution as in the case of cu-zn (discovery of the well known zener peak [18]), or to the precipitates.

In a Cu-3wt:Co alloy, Mondino and schoeck [19] have obtained a relaxation peak after ageings which lead to the coherency loss of the precipitates. The origin of the peak has then been attributed to the relaxation, assisted by the diffusion of the co atoms, of the interface dislocations.

In the same way, Mondino and co-woxkers [20,21] give an account for a peak associated with the semi-coherent $x$ precipitates in Cu-17wt:si. 
On the contrary, the Cu-Fe alloys exhibit a peak associated with coherent precipitates. This peak has been studied by Pelletier $[22,23]$. It disappears when the precipitates become incoherent. Pelletier interpretes then the peak as due to a complex relaxation of zener type in the precipitates of Fe.

A mechanism of stress induced ordering has also been observed in the "ferromagnetic" precipitates of the $\mathrm{Cu}-\mathrm{Ni}$ system $[24,25,26]$.

Conclusions : The diverse examples presented here show that each alloy exhibits an internal friction spectrum more or less complex, which is modified by precipitation. The interpretation of the anelastic relaxations is mainly based on twomechanisms: the reorientation under the applied stress of elastic dipoles (Zener relaxation) and the movement of the precipitates-matrix interfaces. It seems also that the real mechanisms can be more complex than those which are described by the existing models. Effectively, in many cases, these models do not offer a sufficient description of the internal friction behaviour. The involved mechanisms may be different depending on the system which exhibits the peak.

\section{PEAKS DUE TO PRECIPITATES : Theoretical considerations}

"Precipitates peaks" are relaxation peaks which appear associated with the presence in the alloy of precipitates.

Usually, the height of these peaks is proportional to the volume fraction of the precipitates, i.e. to the concentration of the alloy, when precipitation is complete. Hence they differ from the zener peaks, the height of which varies linearly with the square of the concentration.

The activation enerav of these peaks is alwavs liahtlv lower than the diffusion enerav of the solute atoms. Hence the relaxation is controlled bv the movement of solute atoms which are in particular position, for example, near the dislocations. The value of the limit frequency $10^{12}-10^{25} \mathrm{~Hz}$ gives also an account for atoms movements.

\section{Schoeck's theory:}

Taking into account the results obtained in diverse alloys, Schoeck has elaborated in 1969 a theory of the anelasticity due to the precipitates [27].

In his research, schoeck considexs the precipitates as inclusions in the matrix. He determines then the interactions between the precipitates and the applied stress taking into account the theoretical works of Eshelby $[28,29]$. The interaction energy gives the maximum value of the internal friction due to the precipitates.

The conclusions of the schoeck's theory are that only the incoherent or semi-coherent precipitates can give rise to an internal friction peak. This peak would be caused by anelastic relaxations which take place at the interfaces between matrix and precipitates. In the case of semi-coherent precipitates, the anelastic strain is due to the interface dislocations. Coherent precipitates cannot give rise to an internal friction peak. They contribute to the background which increases monotonously with the temperature. An equilikrium value for the relaxation is never reached because the movement of the interfaces depends on the diffusion kinetics which increase with temperature.

Remarks : If the Schoeck's theory is verified in the case of the alloys as Cu-Co [19] where the peak appears only after the coherency loss of the precipitates, it cannot be applied to the system Cu-Fe, where the peak appears with the coherent precipitates and disappears during the coherency loss.

This theory is then too much restrictive with reipect to the conditions of the appearance of a "precipitates peak".

\section{Kohen's theory $[30]$}

At first, Kohen shows that the anelastic strain is always different from zero when the precipitates present an anisotropy in the mobility of their different interfaces. This is, in particular, the case of the semi-coherent precipitates. Incoherent precipitates can give rise to an anelastic relaxation only when their interfaces have 
a glissible structure.

The model considers plate shaped precipitates. At a constant temperature, the precipitate can be characterized by three thermodynamical variables : the shear stress, the solute concentration at the interface and the precipitate diameter. The applied stress induces across the interface a difference in the thermodynamical potential. The precipitate growths then or dissolves in order to reach a new equilibricu state. The movements of the interfaces are controlled by the diffusion of the solute atoms.

When the interface mobility is great, the internal fxiction exhibits a peak, whose half-width is only $13 \%$ greater than the one of a Debye peak.

If the interface mobility goes down, the activation energy is modified. The peak shifts then towards the high temperatures, broadens out and vanishes in the background.

In conclusion, internal friction associated with the precipitates depends on the nature of their interfaces. The anelastic phenomena are only important when the interface has a glissible structure.

Finally, it has to be remarked that the above mentioned theories are not concerned with the possibility of anelastic relaxations inside the precipitates. They are only based on problems related to the interfaces created by precipitation.

\section{The Al-Ag system :}

The Al-Ag alloys have been studied by many authors [31 to 38 ]. After ageing, a stable relaxation peak appears associated with the presence of the $\gamma^{\prime}$ ( $\mathrm{Ag}_{2} \mathrm{Al}-\mathrm{hcp}$ ) precipitates (peak $P_{3}$ on fig. 2).

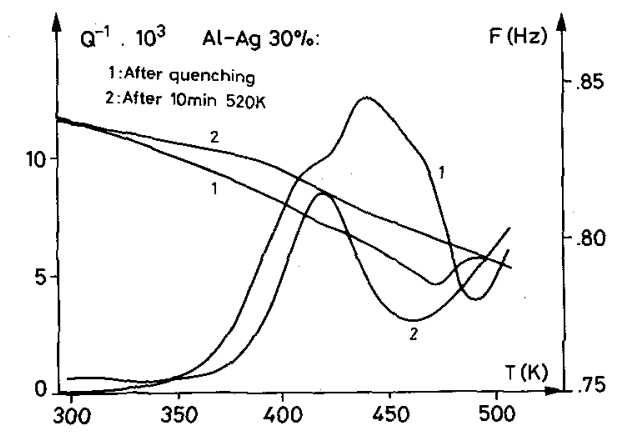

Fig. 2 : Evolution of the internal friction spectrum of an Al-30wtoAg during precipitation $[36]$. the result obtained by schaller [37] in a pure $\gamma$ phase alloy. It is shown that the relaxation peak is maximum in height in a monophased specimen (fig. 3). The peak must then be due to some reorientation under the applied stress of elastic dipoles in the $\gamma^{\prime}$ precipitates [38].

Discussion : This last result shows that the anelastic relaxations associated with the precipitates do not all have the same origin.

If we consider the precipitates peak in aluminium alloys, the temptation is great to search for an universal theory. Effectively, all these peaks appear in the same range of temperature for measurements at low frequency ( 1 1Hz), because their activation energy, which is bound with the diffusion energy of the solute atoms, is not very different in one or the other system.

Though some characteristics of the peaks can be different depending on the alloy. For example, it is possible to compare Al-Ag with Al-Cu. The peak due to the $\gamma^{\prime}$ precipitates in Al-Ag presents a small broadening factor $(\beta=1.12)$ and the limit relaxation 


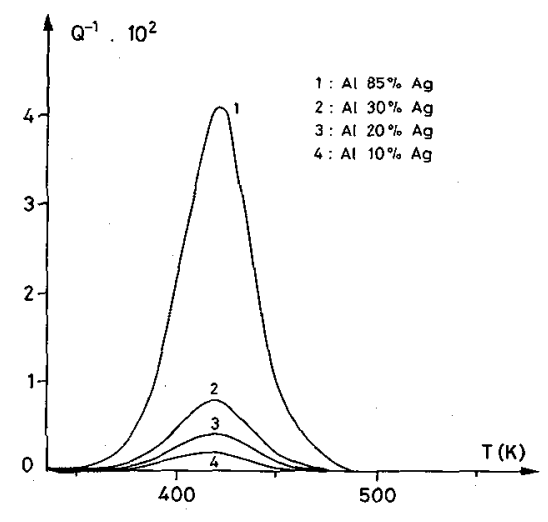

Fig. 3 : The precipitates peak of the Al-Ag alloys is maximum in a pure $\gamma$ phase alloy, i.e. in an A1-85wto $\mathrm{Ag}$.

time $\left(\tau 0=4 \cdot 10^{-15} \mathrm{~s}\right.$ ) is Low [36]. This tends to show that the peak is due to atomic movements.

On the contrary, the peak associated with the $\theta$ ' precipitates in the $A l-C u$ alloys has a greater broadening factor $(\beta=3)$ and the limit relaxation time is higher ( ${ }_{0}=10^{-125 \pm 0.8} \mathrm{~S}$ ) [3].

These characteristics are nearer of those of the peaks associated with the movements of dislocations. Moreover, the $\theta$ ' precipitates peak vanishes during the coherency loss. In this case, it seems that the interface relaxation models are correct.

In conclusion, precipitates peaks cannot be explained by a unique theory. The anelastic relaxations can take place as well at the interfaces as inside the precipitates. This last possibility is of a great interest. Effectively, internal friction is then the technique very well suited to the study of the internal properties of a second phase particles which are dispersed in a matrix.

The particles are excitated by the stress applied through the interfaces. They can give then a response as an anelastic strain which is proportional to the volume fxaction of the second phase.

\section{RECRYSTALLIZATION}

Free energy of a metal increases with the density of defects (mainly dislocations) produced by plastic deformation. The return towards a more stable thermodynamical state is achieved by the annealing out of the defects during the formation of new grains, which present a crystallographic orientation different from the one of the matrix. This transformation is called recrystallization and is usually preceded by a recovery stage (annihilation of some point defects and of dislocations of opposite sign, rearrangement of the dislocations network) [39].

In this case too, internal friction seems to be very well suited to the study of the evolution of the microstructure.

In pure metals, recrystallization exhibits first an increase of the internal friction followed by a subsequent decrease at the end of the transformation. This behaviour has been observed in diverse metals as $\mathrm{Cr}[40], \mathrm{Cd}[41], \mathrm{Fe}[43], \mathrm{Au}[44,45], \mathrm{Ag}[42$ and 46 to 48$]$, Co and $\mathrm{Ni}[49,50]$, and interpreted thanks to the well-known GranatoLücke theory for dislocations damping [51].

As a typical example, one can consider the results obtained in pure silver by Isoré [52]. The internal friction, measured at room temperature and reported as a function of the temperature of the annealings of deformed specimen, presents three stages in its evolution (fig. 4) : a light decrease associated with the recovery stage, a strong increase up to a maximum due to the primaxy recrystallization and finally a decrease during a post.recrystallization stage, which is interpreted as due to the re-arrangement of the dislocations in the recrystallized phase. The strong increase of the internal friction is attributed by Isoré et al [53] to a high degree of mobility of the dislocations in the freshly recrystallized domains behind the migrating grain boundary. Thanks to the Granato-Lücke model, Isore determines than the evolutions during recrystallization of the density " $\Lambda$ " and the loops length " $l$ " of the dislocations.

Rather than measuring the evolutions of the internal friction background, J. Petit et al [54] have studied the recrystallization in $\mathrm{Zr}$ and $\mathrm{Ti}$ through the recovery stages of a peak due to the dislocations. 


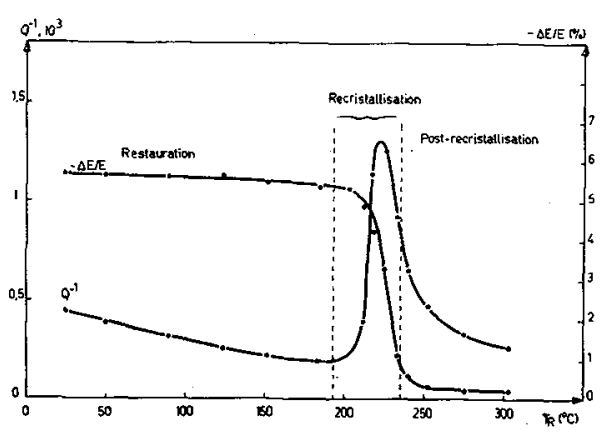

Fig. 4 : Internal friction $\left(Q^{-1}\right)$ and defect of elastic modulus $\left(-\frac{\Delta E}{E}\right)$ of $\mathrm{Ag}$ $99.995 \%$, measured at $20^{\circ} \mathrm{C}$ as a function of the temperature $\left(T_{R}\right)$ of isochronal (1h) annealings. Three stages of evolution appear. (after Isoré et al [52]). friction to the evolution of the dislocations network during recrystallization. As internal friction is affected by the interactions of the dislocations with other defects, it can be interesting to use it for the study of the interactions precipitation-recrystallization in alloys.

\section{RECRYSTALLIZATION IN AI-MN ALLOYS}

The problem of the interactions between precipitation and recrystallization in the Al Mn alloys has received considerable attention in the last few years [59 to 62 ]. In all these works, techniques such as electrical resistivity, hardness, optical and electron microscopy have been used. These techniques allow one to observe the microstructure at each stage of its evolution. But they are not well suited to the study of the dynamical interactions between the dislocations and the second phase particles.

Therefore, Diallo $[63,64,65]$ has studied the recrystallization in Al-Mn alloys by means of internal friction measurements, and obtained the following results.

The heavely deformed Al-0.5 to $2 \mathrm{wt} \% \mathrm{Mn}$ alloys present, during isochronal annealings, two main stages in the evolution of the internal friction spectrum (fig. 5)

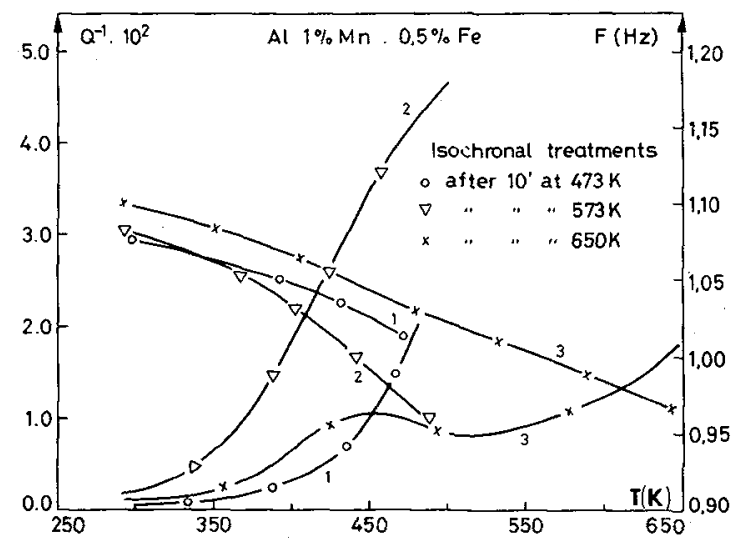

Fig. 5 :

Evolution of the internal friction spectrum of a commercial Al-loMn alloy during isochronal annealings $[63]$. 
The first stage is characterized by an increase in internal friction, observed after annealing at a temperature of $573 \mathrm{~K}$. This increase in internal friction has been attributed to the increase in length of the dislocation loops, when the pinning Mn atoms are clustering to form new precipitates. This stage is then due to precipitation, an interpretation confirmed by the measurement of the residual electrical resistivity and of the thermoelectric power (fig. 6).

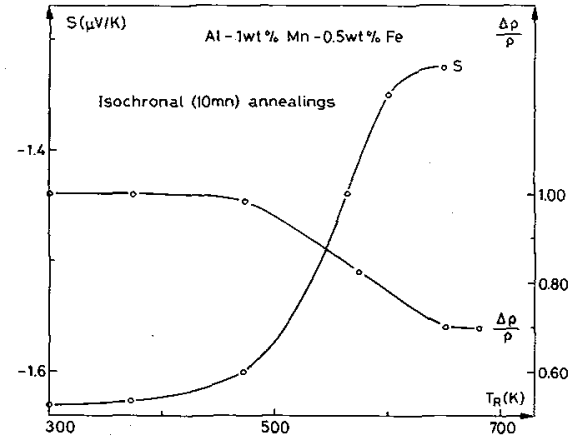

Fig. 6 : Evolution of the electrical resistivity and the thermoelectric power during precipitation in Al-lwt品任 [65].

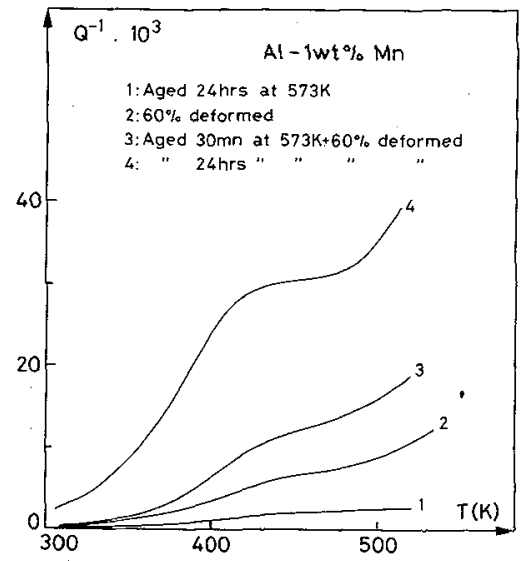

Fig. 7 : Dependance of the peak height and the background on the thermomechanical treatments. Remaxk the effect of deformation.
The second stage appears after ageing at $6650 \mathrm{~K}$. It is associated with a strong decrease in internal friction, due to the reduction of the dislocation density during recrystallization.

This has been confirmed by microscopic observations.

After the decrease of the internal friction, a relaxation peak appears at $2420 \mathrm{~K}$ (Eig.5) In fact, this peak appears already at the first stage of the evolution of the deformed alloy, but is only detectable when the internal friction is relatively weak (fig.8). The existence of this peak seems to be connected with the presence of metastable precipitates of $G_{1}\left(\mathrm{Al}_{12} \mathrm{Mn}, \mathrm{bcc}\right)$ type [60]. Yet, its characteristics are not those of the classical peaks due to precipitates. More precisely its height is not proportional to the concentration of the alloy, but depends on the dislocation density (fig. 7) : the peak is absent in the undeformed specimen. In conclusion, the relaxation peak in the Al-Mn system is associated with the simultaneous presence of dislocations and precipitates.

Diallo has then elaborated a theoretical model, based on a microscopic mechanism of interactions between dislocations and precipitates, the formalism of which is similar to the Schiller's model [66]. It leads to the following expression for the internal Eriction peak :

$$
Q^{-1}=\alpha \Lambda \ell \frac{\omega \tau}{1+\omega^{2} \tau^{2}}
$$

where $\alpha$ is a proportionality constant, $\Lambda$ the dislocation density,

and $\ell$ the dislocations loops length. The high temperature internal friction background has been attributed to an interaction mechanism of the dislocations with the Mn solute atoms. For this case, the model leads to an expression of the type :

$$
Q^{-1} \sim \Lambda \ell e^{-\frac{E}{k T}}
$$

As a consequence the peak and the high temperature internal friction background are both sensitive to the evolution of the dislocation microstructure. The product $\Lambda l$ gives then a measure of the total driving force for recrystallization In effect, the self driving force due to the dislocation elastic energy is proportional to $\Lambda$, while the dragging force due to the Mn solute atoms, which pin the dislocations, is proportional to the inverse of the length $\mathrm{l}$. Consequently the higher the peak or the high temperature internal friction background, the lower the recrys- 
tallization temperature (fig. 8).

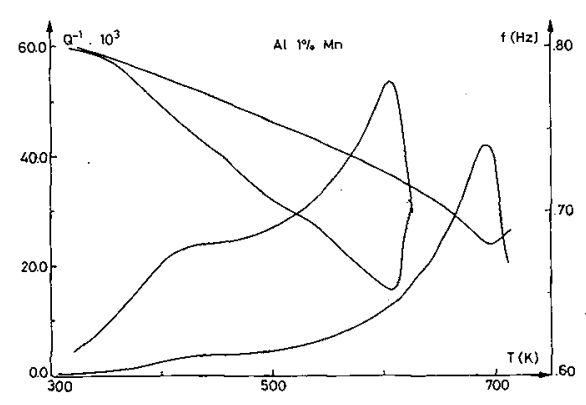

Fig. 8 : Internal friction spectrum of two Al-lwtsmn specimen. A great relaxation peak leads to a low recrystallization temperature.
In the Al-Mn alloys, precipitation favours recrystallization, because it decreases the dragging forces due to the solute atoms which pin the dislocations. In this case, internal friction increases during precipitation. On the contrary, in Al-Ag alloys, recrystallization is impeded by precipitation which gives rise to an increase of the dragging forces due to the pinning of the dislocations by the precipitates [36]. In this case, according to Diallo's intexpretation, the high temperature internal friction background decreases during precipitation.

Discussion : All the results found in the $1 i-$ terature show that internal friction is affected by recristallization through the evolutions of the dislocations microstructure. In addition, the results obtained by Diallo [65] show that the advantage of using internal friction is the possibility to study the dynamical aspects of the re-arrangement of the dislocations. This is not possible with classical techniques.

The internal friction results obtained in Al-Mn show that recrystallization is conditioned by the Iiberation of the dislocations which have to be re-arranged. Effectively, if the dislocations cannot move, the formation of the subgrains boundaries, which are at the origin of the nucleation of the new grains [39], is impossible and consequently recrystalizization cannot start as it was the case in Al-Ag [36]. From this point of view, dislocations play the most prominent part in the nucleation of the primary recrystalization. Internal friction, which measures the product $\Lambda 2$ [65], is then sensitive to the driving force for nucleation.

Before recrystallization, the dislocations density $\Lambda$ can be considered as constant. Thus, the variations of the internal friction give an account for the evolution of the dragging forces which act on the dislocations.

Therefore internal friction must increase before recrystallization starts. In this direction, Diallo's results are confirmed by the results obtained by petit et al in $\mathrm{zr}$ and $\mathrm{Ti}$ [54]. On the contrary, Isoré [52,53] attributes the increase of internal friction to the appaxition of domains which are already recrystallized.

But, in this case, the mode of nucleation of the new grains is different. Effectively, the deformation of the samples measured by Isore is small ( $10 \%$ ), and in this case the nucleation can be achieved by the migration of a grain boundary which was pre-existent to the plastic deformation [39]. Effectively, Isore [53] has observed the nucleation of new grains on the "old" grain boundaries. This mechanism does not require the formation of subgrains during the recovery stage. It would be interesting to study more in details the different modes of nucleation of the new grains by the method developed by Diallo et al [63 to 65$]$.

\section{CONCLUSIONS}

Internal friction is sensitively affected by precipitation and recrystallization. The results found in the literature show that the origins of the anelastic phenomena can be different depending on the material.

For example, the peaks associated with the precipitates can be due either to interfaces mechanisms as in Al-Cu alloys [5] or to relaxations which take place in the precipitates as in Al-Ag alloys [37]. Internal friction is then a powerful method for studying the problems related to the coherency of the interfaces as in the Cu-Co system [19] or the internal properties of second phase particles dispersed in the matrix. This last aspect has already been used with success by Millet [67] in the study of the damping capacity of grey cast iron : here the damping is due to internal friction me- 
chanisms in the graphite precipitates.

Now, if the precipitation stages can be revealed by the evolution of the internal friction spectrum, the method is not well suited to the study of the first stages of the rapid decomposition of the quenched solid solutions. In this case it is nearly impossible to measure the internal friction under equilibrium conditions.

In recrystalization, internal friction would have to be used for the study of the dynamical interactions between the dislocations and other defects. Effectively, the results obtained in this field show clearly the prominent part which is played by the dislocatious in the nucleation of the new grains.

Internal friction seems then to be sensitive to the driving force acting on the dislocations which have to be re-arranged. It would be of a great interest to search further for the microscopic mechanisms which can give an account for the thermodynamical models of recrystallization. Such a research requires naturally the comparisons of the results obtained by different techniques.

In this field, and more generally in diffusion assisted phase transformations, internal friction is advantageous in the problems, where the dislocations mobility is involved.

\section{REFERENCES}

[1] GOBIN P.F., J. de Physique 32 (1971) C2-65

[2] WOIRGARD J., RIVIERE A., DE FOUQUET J., J. de Physique 42 (1981) C5-407

[3] BERRY B.S., NOWICK A.S., NACA TN 4225, Yale U (1958)

[4] BERRY B.S., Acta Met. 9 (1961) 98

[5] HANAUER C., MERLIN J., PEREz J. et al., Mém. Sci. Rev. Mét. 69 (1972) 653

[6] KISS S., KEDVES F.J., HARANGOZO I.Z., Nuovo Cimento, 33B (1 $\overline{976)} 380$

[7] FOUQUET F., MERLE P., KOHEN M. et al., Áta Met. 27 (1979) 315

[8] ZENER C., Phys. Rev. 71 (1947) 34

[9] NILSON W.G., Can. J. Phys. 39 (1961) 119

[10] DEY B.N., QUADER M.A.; Can. J. Phys. 43 (1965) 1347

[I1] BELSON J., LEMERCIER D., MOSER P., VIGIER P. , Phys. Stat. Sol. 40 (1970) 647

[12] LECLATRE A.D., LOMER W.M., Acta Met. 2 (1954) 731

[13] ENTWISTLE K.M., FULLER P., BROUGH I., Acta Met. 26 (1978) 1055

[14] ELLIOT R., ENTWISTIE K.M., Acta Met. 12 (1964) 215

[15] WILLIAMS K.J., Acta Met. 15 (1967) $\overline{393}$

[16] NOWICK A.S., J. Appl. Phys. 22 (1951) 925

[17] MERLIN J., MONDINO M., LEROY J., Phys. Stat. Sol. 21 (1974) 435

[18] ZENER C., Trans. AIME, 192 (1943) 122

[19] MONDINO M., SCHOECK G., Phys. Stat. Sol. 6 (1971) 665

[20] MONDINO M. . LARDONE C., Scripta Met. 6 (1972) 1109

[21] MONDINO M., GUGELMEIER R., "Internal Friction and Ultrasonic Attenuation in Solids " ed. by C.C. Smith, Pergamon Press (1980) 317

[22] PELLETIER J.M., BORELLY R., MERLIN J., Mém. Sci. Rev. Met. 72 (1975) 431

[23] PELLETIER J.M.. Thesis, INSA-Lyon (1975)

[24] DEY B.N., J. Appl. Phys. 35 (1964) 3621

[25] DEY B.N., Scripta Met. 2 (1968) 501

[26] ROBERTS J.T.A., BARRAND P., Scripta Met. 3 (1969) 29

[27] SCHOECK G., Phys. Stat. Sol. 32 (1969) 651

[28] ESHELBY J.D., Proc. Roy. SOc. A 241 (1957) 376

[29] EShElBY J.D., Prog. Solid. State Phys. 3 (1956) 79

[30] KOHEN M., FANTOZZI G., FOUQUET F. et al, "Internal Friction and ultrasonic Attenuation in Crystalline Solids" ed. by D. Lenz, K. Lücke, Vol. I, Springer Verlag (1975) 276-282

[31] DAMASK A.C., NOWICK A.S., J. App1. Phys. 26 (1955) 1165

[32] MINER R.E., WILSON T.L., JACKSON J.M., I'rans. AIME 245 (1969) 1375

[33] SCHOECK G., BISOGNI E., Phys. Stat. Sol. 32 (1969) 31

[34] POSTNIKOV V.S., SHARSHAKOV I.M., YEVSUKOV V.A., Fiz. Metalloved 32 (1971) 195 
[35] MERLIN J., MERLE P., FOUQUET F., PELLETIER J.M., Scripta Met. 12 (1978) 227

[36] SCHAller R., BENOIT W., Mém. Sci. Rev. Mét. 76 (1979) 521

and SCHALLER R., Thesis, EPF-Lausanne (1980)

[37] SCHALLER R., BENOIT W. , "Internal Friction and Ultrasonic Attenuation in Solids" ed. by C.C. Smith, Pergamon Press (1980) 311

[38] SCHALLER R., BENOIT W., J. de Physique 42 (1981) C5-881

[39] "Recrystallization of Metallic Materials" ed. by F. Haessner, Riederer Verlag (1978)

[40] DE MORTON M.E., Trans. AIME, 221 (1961) 395

[41] KAMEL R., ATTIA E.A., Phil. Mag. 4 (1959) 644

[42] KAMEL R., ATTIA E.A., Acta Met. 9 (1961) 1047

[43] ROBINSON P.M., RICHARDS P.N., Phil. Mag. 11 (1965) 407

[44] JALANTI T., BENOIT W., Helv. Phys. Acta 4I (1968) 1290

[45] JALANTI T., ISORE A., Helv. Phys. Acta 43 (1970) 463

[46] FORNEROD R.C., Mém. Sci. Rev. Mét. 66 (1969) 157

[47] ISORE A., BENOIT w., Mém. Sci. Rev. Mét. 69 (1972) 223

[48] ISORE A., BENOIT W., MERCIER O,, Scripta Met. 6 (1972) 933

[49] DUBOIS B., BOUQUET G., J. de Physique, 32 (1971) C2-201

[50] BOUQUET G., DUBOIS B., Mém. Sci. Rev. Mét. 70 (1973) 693

[51] GRANATO A., LUECKE K., J. Appl. Phys. 27 (1956) 583

[52] ISORE A., BENOIT W., STADELMANN P., Phil. Mag. 34 (1976) 811

[53] ISORE A., MERCIER O., BENOIT W., Mém. Sci. Rev. Mét. 70 (1973) 509

[54] PETIT J., QUINTARD M., MAZOT P., DE FOUQUET J., Mém. Sci. Rev. Mét. 70 (1973) 753

[55] YAMANE T., Trans. AIME 227 (1963) 1024

[56] YAMANE T., MIMA G., VEDA J., Trans. JIM 5 (1964) 185

[57] YAMANE T., VEDA J., Trans. JIM 4 (1963) 245

[58] YAMANE T., Trans. JIM $\underline{6}$ (1965) 67

[59] "Recrystallization and grain growth of multi-phase phase particle containing materials" ed. by N. Hansen, A.R. Jones, T. Leffers, Ris $\varnothing$ (1980)

[60] FURRER P., HAUSCH G., Met. Sci. 13 (1979) 155

[61] MORRIS P.L. , DUGGAN R.J., Met. Sci. 12 (1978) 1

[62] LLOYD D.J., Met. Sci. 16 (1982) 304

[63] DIALLO C., MONDINO M., BENOIT W., J. de Physique 42 (1981) C2-957

[64] DIALLO C., SCHALLER R., BENOIT W., MONDINO M., Mém. Sci. Rev. Mét. 79 (1982) 33

[65] DIALLO C., Thesis EPF-Lausanne (1983)

[66] SCHILLER P.. Phys. Stat. Sol. 5 (1964) 391

[67] MILLET P., SCHALLER R., BENOIT W., J. de Physique 42 (1981) C5-929 